\title{
NOVAS CONFIGURAÇÕES DA DIVISÃO SEXUAL DO TRABALHO
}

\author{
HELENA HIRATA \\ helenahirata99@aol.com \\ DANIÈLE KERGOAT
}

daniele@wanadoo.fr

Genre, Travail, Mobilités, Centre National de la Recherche Scientifique

\section{Tradução: Fátima Murad}

\begin{abstract}
RESUMO
O conceito de divisão sexual do trabalho já tem uma longa história. Em primeiro lugar esboçaremos a gênese do conceito no contexto francês, citando pesquisas que o reivindicam. Proporemos nossa própria definição do conceito, que nos servirá para analisar a evolução atual das modalidades da divisão sexual do trabalho. Em seguida, retornaremos de forma mais precisa aos modelos que organizam as relações entre esferas doméstica e profissional. Indicaremos o aparecimento de um novo modelo, o da "delegação", para concluir com uma análise crítica da "conciliação" de tarefas.

DIVISÃO SEXUAL DO TRABALHO - GÊNERO - FAMÍLIA - MULHERES
\end{abstract}

\section{ABSTRACT}

NEW TRENDS IN THE SEXUAL DIVISION OF LABOR. The concept of the sexual division of labor has a long history. First of all, we will outline the origin of the concept in the French context, quoting some research studies that claim it. We will also suggest our own definition of the concept, which will help us analyze the present characteristics of the sexual division of labor. Next, in a more precise way, we will bring the discussion back to the models that organize the relations between the domestic and professional spheres. We will point to the emergence of a new model, the so-called "delegation" model, in order to conclude with a critical analysis of "conciliation" of tasks.

SEXUAL DIVISION OF LABOUR - GENDER - FAMILY - WOMEN

A primeira parte desta exposição foi redigida par Danièle Kergoat e a segunda, por Helena Hirata. 
O termo "divisão sexual do trabalho" aplica-se na França a duas acepções de conteúdos distintos. Trata-se, de um lado, de uma acepção sociográfica: estuda-se a distribuição diferencial de homens e mulheres no mercado de trabalho, nos ofícios e nas profissões, e as variações no tempo e no espaço dessa distribuição; e se analisa como ela se associa à divisão desigual do trabalho doméstico entre os sexos.

Esse tipo de análise foi e continua sendo indispensável: por exemplo, a construção de indicadores confiáveis para medir a igualdade profissional homens/mulheres é um verdadeiro desafio político na França. Mas, a nosso ver, falar em termos de divisão sexual do trabalho deveria permitir ir bem além da simples constatação de desigualdades. E aqui se chega à segunda acepção, segundo a qual falar em termos de divisão sexual do trabalho é: I . mostrar que essas desigualdades são sistemáticas e 2. articular essa descrição do real como uma reflexão sobre os processos mediante os quais a sociedade utiliza essa diferenciação para hierarquizar as atividades, e portanto os sexos, em suma, para criar um sistema de gênero.

projeto coletivo que serviu de base na França às primeiras aparições do termo "divisão sexual do trabalho" tinha uma ambição maior que denunciar desigualdades: sob o impulso do movimento feminista, tratava-se nem mais nem menos de repensar o "trabalho". O ponto de ancoragem dessa ambição era a idéia de que o trabalho doméstico era um "trabalho" e que, portanto, a definição deste deveria obrigatoriamente incluir aquele. Não dava para imaginar para onde isso nos levaria... A questão não era simplesmente somar trabalho profissional e trabalho doméstico. Para ser mais precisas: ao fazer essa soma, logo nos demos conta de que as costuras do paletó "trabalho", feito sob medida por e para as crenças economicistas, cediam facilmente nas cavas. Assim, pouco a pouco, caminhamos para uma definição não mais centrada na valorização do capital, e sim naquilo que alguns chamaram de "produção do viver" (Hirata, Zarifian, 2000). Vamos medir o caminho percorrido...

A idéia de iniciarmos este artigo distinguindo as duas maneiras de pensar e de estudar a divisão sexual do trabalho deve-se a duas razões. A primeira é que, desde o nascimento do conceito há cerca de trinta anos, se observa uma tensão entre, de um lado, análises que pensam mais em termos de constatação de desigualdades entre homens e mulheres, e de acúmulo, de soma dessas desigualdades (cf. a noção atual de conciliação de tarefas), e, de outro 
lado, análises que procuram remontar à nascente dessas desigualdades e, portanto, compreender a natureza do sistema que dá origem a elas. Subentendese que é nesse quadro de reflexão que nos inscrevemos.

A segunda razão é que, sempre que se tenta fazer um balanço da divisão sexual do trabalho em nossas sociedades, se chega à mesma constatação em forma de paradoxo: nessa matéria, tudo muda, mas nada muda. Por isso, nesta exposição, procuraremos desconstruir esse paradoxo.

\section{A GÊNESE DO CONCEITO}

Embora a divisão sexual do trabalho tenha sido objeto de trabalhos precursores em diversos países, foi na França, no início dos anos 1970, sob o impulso do movimento feminista, que surgiu uma onda de trabalhos que rapidamente assentariam as bases teóricas desse conceito. Primeiro na Etnologia (Mathieu, 1991; Tabet, 1998), depois na Sociologia e na História.

Foi com a tomada de consciência de uma "opressão" específica que teve início o movimento das mulheres: torna-se então coletivamente "evidente" que uma enorme massa de trabalho é efetuada gratuitamente pelas mulheres, que esse trabalho é invisível, que é realizado não para elas mesmas, mas para outros, e sempre em nome da natureza, do amor e do dever materno. A denúncia (pensemos no nome de um dos primeiros jornais feministas franceses: Le Torchon Brûle*) se desdobrará em uma dupla dimensão: "estamos cheias" (era a expressão consagrada) de fazer o que deveria ser chamado de "trabalho", de deixar que tudo se passe como se sua atribuição às mulheres, e apenas a elas, fosse natural, e que o trabalho doméstico não seja visto, nem reconhecido.

Em pouquíssimo tempo, surgiram as primeiras análises dessa forma de trabalho nas ciências sociais. Foi o caso, para citar apenas dois corpus teóricos, do "modo de produção doméstico" (Delphy, 1998) e do "trabalho doméstico" (Chabaud-Rychter, Fougeyrollas-Schwebel, Southonnax, 1985). Pouco a pouco, as análises passaram a abordar o trabalho doméstico como atividade de trabalho tanto quanto o trabalho profissional. Isso permitiu considerar "si-

* Expressão da língua francesa que poderia ser traduzida como "fechou o tempo", ou "a coisa está feia" (N. da T.). 
multaneamente" as atividades desenvolvidas na esfera doméstica e na esfera profissional, o que abriu caminho para se pensar em termos de "divisão sexual do trabalho".

Assim, inicialmente, a divisão sexual do trabalho tinha o estatuto de articulação de duas esferas. Porém, essa noção de articulação logo se mostra insuficiente, o que nos levou a um segundo nível de análise: a conceitualização dessa relação social recorrente entre o grupo dos homens e o das mulheres. Essa foi a origem do que nós, francesas, chamamos de "relações sociais de sexo". Não desenvolveremos essa noção, pois esse não é nosso objetivo aqui, embora, na França, ela seja indissociável da teorização em termos de divisão sexual do trabalho.

Essa nova maneira de pensar o trabalho teve muitas conseqüências. Por uma espécie de efeito boomerang, depois que "a família", na forma de entidade natural, biológica, se esfacelou para ressurgir prioritariamente como lugar de exercício de um trabalho, foi a vez de implodir a esfera do trabalho assalariado, pensado até então apenas em torno do trabalho produtivo e da figura do trabalhador masculino, qualificado, branco.

Esse duplo movimento impulsionou na França e em vários países uma floração de trabalhos que utilizaram a abordagem da divisão sexual do trabaIho para repensar o trabalho e suas categorias, suas formas históricas e geográficas, a inter-relação de múltiplas divisões do trabalho socialmente produzido. Essas reflexões levaram a um questionamento radical da sociologia da família e do paradigma funcionalista que the servia de base. No que se refere à sociologia do trabalho', elas permitiram retomar noções e conceitos como de qualificação, produtividade, mobilidade social e, mais recentemente, de competência, e abriram novos campos de pesquisa: relação de serviço e, hoje, trabalhos de cuidado pessoal, mixidade no trabalho, acesso das mulheres às profissões executivas de nível superior, temporalidades sexuadas, vínculos entre políticas de emprego e políticas para família etc.

Contudo, esse balanço, por mais positivo que seja, não deve ser confundido com um grito de vitória. Pois, simultaneamente a esse trabalho de construção teórica, entrou em declínio a força subversiva do conceito de divi-

I. Sobre esse longo trabalho de desconstrução e de reconstrução, pode-se reportar ao artigo de Hirata e Kergoat (2005). 
são sexual do trabalho. Agora o termo é usual no discurso acadêmico das ciências humanas e, particularmente, na Sociologia. De maneira geral, é desprovido de qualquer conotação conceitual, e remete apenas a uma abordagem que descreve os fatos, constata as desigualdades, mas não organiza esses dados de forma coerente. $O$ trabalho doméstico, que já foi objeto de numerosos trabaIhos, quase não é mais estudado; mais precisamente, ao invés de se utilizar esse conceito para questionar a sociedade salarial (Fougeyrollas-Schwebel, 1998), fala-se em termos como "dupla jornada", "acúmulo" ou "conciliação de tarefas", como se fosse apenas um apêndice do trabalho assalariado. Voltaremos a isto na seqüência desta exposição.

\section{UMA DEFINIÇÃO DO CONCEITO}

É, portanto, na perspectiva dinâmica inicial que queremos situar nosso referencial teórico. A divisão sexual do trabalho é a forma de divisão do trabaIho social decorrente das relações sociais entre os sexos; mais do que isso, é um fator prioritário para a sobrevivência da relação social entre os sexos. Essa forma é modulada histórica e socialmente. Tem como características a designação prioritária dos homens à esfera produtiva e das mulheres à esfera reprodutiva e, simultaneamente, a apropriação pelos homens das funções com maior valor social adicionado (políticos, religiosos, militares etc.).

Sobre essa definição, todo mundo, ou quase, está de acordo. Contudo, do nosso ponto de vista, era necessário ir mais longe no plano conceitual. Por isso, propusemos distinguir claramente os princípios da divisão sexual do trabalho e suas modalidades.

Essa forma particular da divisão social do trabalho tem dois princípios organizadores: o princípio de separação (existem trabalhos de homens e trabalhos de mulheres) e o princípio hierárquico (um trabalho de homem "vale" mais que um trabalho de mulher). Esses princípios são válidos para todas as sociedades conhecidas, no tempo e no espaço. Podem ser aplicados mediante um processo específico de legitimação, a ideologia naturalista. Esta rebaixa o gênero ao sexo biológico, reduz as práticas sociais a "papéis sociais" sexuados que remetem ao destino natural da espécie.

Se os dois princípios (de separação e hierárquico) encontram-se em todas as sociedades conhecidas e são legitimados pela ideologia naturalista, isto não 
significa, no entanto, que a divisão sexual do trabalho seja um dado imutável. Ao contrário, ela tem inclusive uma incrível plasticidade: suas modalidades ${ }^{2}$ concretas variam grandemente no tempo e no espaço, como demonstraram fartamente antropólogos e historiadores(as). O que é estável não são as situações (que evoluem sempre), e sim a distância entre os grupos de sexo. Portanto, esta análise deve tratar dessa distância, assim como das "condições", pois, se é inegável que a condição feminina melhorou, pelo menos na sociedade francesa, a distância continua insuperável.

Essa distinção entre princípios e modalidades e a insistência sobre a noção de distância é que permitem desconstruir o paradoxo de que falávamos no início: tudo muda, mas nada muda.

\section{NOVAS CONFIGURAÇÕES DA DIVISÃO SEXUAL DO TRABALHO}

Como dissemos, a divisão sexual do trabalho tem uma incrível plasticidade. É nessa perspectiva que citaremos algumas das configurações que assume a divisão sexual do trabalho nesta época de fortes turbulências.

I. Trata-se antes de tudo da aparição e do desenvolvimento, com a precarização e a flexibilização do emprego, de "nomadismos sexuados" (Kergoat, 1998): nomadismo no tempo, para as mulheres (é a explosão do trabalho em tempo parcial, geralmente associado a períodos de trabalho dispersos no dia e na semana); nomadismo no espaço, para homens (provisório, canteiros do BTP* e do setor nuclear para os operários, banalização e aumento dos deslocamentos profissionais na Europa e em todo o mundo para executivos). Constata-se que a divisão sexual do trabalho amolda as formas do trabalho e do emprego e, reciprocamente, que a flexibilização pode reforçar as formas mais estereotipadas das relações sociais de sexo.

2. O segundo exemplo é o da priorização do emprego feminino, que ilustra bem o cruzamento das relações sociais. Desde o início dos

2. Por "modalidades", entendemos, por exemplo, a concepção do trabalho reprodutivo, o lugar das mulheres no trabalho mercantil etc.

* Banque du Bâtiment et Travaux Publics [Banco da Construção e Obras Públicas] (N. da T.). 
anos 1980, o número de mulheres contabilizadas pelo Institut National de la Statistique et des Études Économiques - Insee (pesquisas de emprego) como "funcionários e profissões executivas de nível superior" mais do que dobrou3; cerca de 10\% das mulheres ativas são classificadas atualmente nessa categoria. Simultaneamente à precarização e à pobreza de um número crescente de mulheres (elas representam 46\% da população ativa, mas são 52\% dos desempregados e $79 \%$ dos baixos salários), observa-se, portanto, o aumento dos capitais econômicos, culturais e sociais de uma proporção não desprezível de mulheres ativas. Assiste-se também ao aparecimento, pela primeira vez na história do capitalismo, de uma camada de mulheres cujos interesses diretos (não mediados como antes pelos homens: pai, esposo, amante) opõem-se frontalmente aos interesses daquelas que foram atingidas pela generalização do tempo parcial, pelos empregos em serviços muito mal remunerados e não reconhecidos socialmente e, de maneira mais geral, pela precariedade.

Mas a análise não pode parar por aqui, e esse será o objeto de nosso terceiro ponto:

3. As mulheres das sociedades do Norte trabalham cada vez mais e, com uma freqüência cada vez maior, são funcionárias e investem em suas carreiras. Como o trabalho doméstico nem sempre é levado em conta nas sociedades mercantis, e o envolvimento pessoal é cada vez mais solicitado, quando não exigido pelas novas formas de gestão de empresas, essas mulheres para realizar seu trabalho profissional precisam externalizar "seu" trabalho doméstico. Para isso, podem recorrer à enorme reserva de mulheres em situação precária, sejam francesas ou imigrantes.

Essa demanda, maciça no âmbito europeu, criou um imenso alento para as mulheres migrantes que chegam aos países do Norte com a esperança de conseguir um emprego de serviço (no cuidado de crianças e idosos, no em-

3. Os números desse item foram extraídos do Insee, 2003. 
prego doméstico etc.). Essas mulheres, muitas vezes diplomadas, entram em concorrência direta com as dos países de origem, que têm situação precária e pouco estudo.

Duas relações sociais entre mulheres, inéditas historicamente, estabelecem-se dessa maneira: uma relação de classe entre as mulheres do Norte, empregadoras, e essa nova classe servil; uma relação de concorrência entre mulheres, todas precárias, mas precárias de maneira diferente, dos países do Norte e dos países do Sul e, logo também, de "cores" diferentes com a chegada a esse mercado de mulheres dos países do Leste.

As relações étnicas começam assim a ser remodeladas através das migrações femininas e da explosão dos serviços a particulares. As relações de gênero também se apresentam de uma forma inédita: a externalização do trabalho doméstico tem uma função de apaziguamento das tensões nos casais burgueses dos países do Norte (e em inúmeros países urbanos do Sul, mas, nesse caso, trata-se de movimentos migratórios internos no país em questão) e permite igualmente maior flexibilidade das mulheres em relação à demanda de envolvimento das empresas. Em um plano mais geral, isso permite às sociedades do Norte fazer vista grossa a uma reflexão sobre o trabalho doméstico. Mas essa pacificação das relações sociais nos casais e nas empresas não ajuda a avançar nem um pouco na luta pela igualdade. Ao contrário, ela tem sobretudo uma função regressiva a esse respeito, pois funciona no nível do mascaramento e da negação. Ao mesmo tempo, as relações de classe são exacerbadas numericamente, pela maior quantidade de indivíduos, homens e mulheres, engajados nesse tipo de relação e, concretamente, pelo contato físico - por meio do trabalho doméstico - entre mulheres em situação precária (do ponto de vista econômico e/ou legal) e mulheres abonadas.

Para resumir, pode-se dizer que os pontos fortes dessas novas modalidades da divisão sexual do trabalho são os seguintes:

- a reorganização simultânea do trabalho no campo assalariado e no campo doméstico. $\bigcirc$ que remete, no que diz respeito a este último, à externalização do trabalho doméstico, mas também à nova divisão do trabalho doméstico (o maior envolvimento de certos pais é acompanhado de um envolvimento quase exclusivo no trabalho parental);

- duplo movimento de mascaramento, de atenuação das tensões nos 
casais burgueses, de um lado, e a acentuação das clivagens objetivas entre mulheres, de outro: ao mesmo tempo em que aumenta o número de mulheres em profissões de nível superior, cresce o de muIheres em situação precária (desemprego, flexibilidade, feminização das correntes migratórias).

Esses movimentos desenvolvem-se em um nível material (a externalização), mas, evidentemente, estendem-se às representações ad hoc (os "novos pais", o casal visto como lugar de negociação entre dois indivíduos iguais de direito e de fato).

Contudo, é preciso rever agora a outra modalidade de teorização, a da divisão sexual do trabalho como "vínculo social", pois é ela que fundamenta a tese, que hoje adquiriu o estatuto de política - e de política européia a partir da cúpula de Luxemburgo em 1997 (cf. Fagnani, Letablier, 2005, p. I7I) -, da "conciliação" vida familiar/vida profissional - política fortemente sexuada, visto que define implicitamente um único ator (ou atriz) dessa "conciliação": as muIheres, e consagra o statu quo segundo o qual homens e mulheres não são iguais perante o trabalho profissional. Na própria essência dessa política há um paradoxo: a vontade de chegar à igualdade pela promoção da conciliação (Nouvelles Questions Féministes, 2004, p.8).

\section{VÍNCULO SOCIAL E RELAÇÕES ENTRE ESFERAS DOMÉSTICA E PROFISSIONAL: MODELOS EM QUESTÃO}

A idéia de uma complementaridade entre os sexos está inserida na tradição funcionalista da complementaridade de papéis. Remete a uma conceitualização em termos de "vínculo social" pelos conteúdos de suas noções (solidariedade orgânica, conciliação, coordenação, parceria, especialização e divisão de tarefas). A abordagem em termos de "complementaridade" é coerente com a idéia de uma divisão entre mulheres e homens do trabalho profissional e doméstico e, dentro do trabalho profissional, a divisão entre tipos e modalidades de empregos que possibilitam a reprodução dos papéis sexuados. Ela aparece de formas diversas.

No "modelo tradicional": papel na família e papel doméstico assumidos inteiramente pelas mulheres, e o papel de "provedor" sendo atribuído aos 
homens. No "modelo de conciliação": cabe quase que exclusivamente às muIheres conciliar vida familiar e vida profissional. A definição de Jacqueline Laufer para esse modelo de conciliação é a seguinte:

...ele visa articular as atividades familiares e domésticas com a vida profissional. É uma condição necessária da igualdade de oportunidades entre mulheres e homens, em particular no âmbito profissional [...]. Uma eventual recomposição e uma nova divisão de papéis se realizariam, assim, não mais em detrimento das mulheres, mas em benefício comum de homens e mulheres. (1995, p. I64)

Contudo, entre modelo e realidade das práticas sociais pode haver uma grande distância, e em geral incumbe apenas às mulheres operar essa conciliação. Essa abordagem deu margem a várias críticas na França. Hoje, certos pesquisadores propõem substituir "conciliação", ou mesmo "articulação", por "conflito", "tensão", "contradição" para evidenciar a natureza fundamentalmente conflituosa da incumbência simultânea de responsabilidades profissionais e familiares às mulheres.

Aparece ainda no "paradigma da parceria", que presume a igualdade de estatutos sociais entre os sexos - preconizada na $4^{a}$ Conferência Mundial sobre as Mulheres, organizada pela Organização das Nações Unidas em Pequim em 1995. Esse princípio de parceria considera mulheres e homens como parceiros (e portanto decorre mais de uma lógica de conciliação de papéis que do conflito e da contradição) e as relações entre eles mais em termos de igualdade que de poder. Esse paradigma da parceria poderia alimentar uma prática de divisão das tarefas domésticas no casal - no plano individual -, porém as pesquisas de emprego do tempo realizadas pelo Insee na França, em 1986 e 1999 (por exemplo, Brousse, 1999), mostram que a realidade das práticas sociais não confirma a atualidade desse modelo.

Figura finalmente no "modelo da delegação". Queremos desenvolver aqui a hipótese da emergência desse quarto modelo, que substitui ou se sobrepõe ao "modelo da conciliação" vida familiar/vida profissional na França.

A emergência desse modelo se deve à polarização do emprego das mulheres (Hakim, 1996) e ao crescimento da categoria de profissões de nível superior e de executivas; elas têm ao mesmo tempo a necessidade e os meios de delegar a outras mulheres as tarefas domésticas e familiares. $\bigcirc$ modelo da 
delegação, de resto, tornou-se possível graças ao aumento acelerado dos empregos em serviços, como já mostramos.

É essa expansão dos empregos em serviços nos países capitalistas ocidentais, tanto desenvolvidos como semi-industrializados e em vias de desenvolvimento, como o Brasil (Sorj, 2004), que oferecem novas "soluções" para o antagonismo entre responsabilidades familiares e profissionais.

\section{EXPERIÊNCIA DA “CONCILIAÇÃO” OU DA “DELEGAÇÃO” DAS EMPREGADAS EM SERVIÇOS}

Na perspectiva das faxineiras, empregadas domésticas, babás e cuidadoras, o que representariam os termos conciliação e delegação ${ }^{4}$ ? Elas também realizam uma delegação do trabalho doméstico e familiar a outras mulheres, mas com conseqüências muito diferentes sobre a vivência dessas mulheres e de seus filhos, como mostram as pesquisas sobre a migração internacional de empregadas domésticas (Parreñas, 2001 ; Ehrenreich, Hochschild, 2003). De fato, a internacionalização do trabalho reprodutivo como uma das conseqüências da externalização crescente do trabalho doméstico nos países capitalistas desenvolvidos engendra uma relação Norte-Sul em que a servidão doméstica provoca para a migrante uma ruptura da relação mãe-filho: "diferentemente do que ocorre com os empregadores do Primeiro Mundo próspero, ela não pode viver com sua família e, ao mesmo tempo, incumbir-se dela economicamente ${ }^{5}$. Essas migrantes do Sul, para fazer "o trabalho das mulheres" do Norte, deixam seus próprios filhos aos cuidados das avós, irmãs, cunhadas, e às vezes só voltam para casa depois de longos períodos, o que acarreta "o traumatismo inevitável dos filhos que deixaram em seu país". Aprofundar a análise da situação das mulheres que tornam possível a "conciliação", e mesmo a "delegação", é essencial para avançar no sentido de uma eventual plataforma - "agenda" na expressão de Ehrenreich e Hochschild - comum entre essas mulheres e as mulheres do Norte que delas dependem.

4. Para a vivência da "conciliação" desta última categoria, ver Lapeyre e Le Feuvre, 2004.

5. Ehrenreich, Hochschild, 2003, p.2. 


\section{POLÍTICAS FAMILIARES E "CONCILIAÇÃO”}

A política familiar francesa atual pode ser definida como uma "política de conciliação", "destinada a facilitar a articulação entre trabalho e vida familiar" (Fagnani, Letablier, 2005, p.167). Como dizem estas últimas, ela continua a excluir os homens dessa problemática, prosseguindo em uma via "maternalista".

As políticas familiares, como a Allocation Parentale d'Education [Subsídio Parental de Educação] - APE -, são políticas de emprego: a interdependência (Devreux, 2000, p.70) dessas duas políticas já foi destacada a partir do estudo de políticas sociais para o caso da França (Devreux, 2000; Fagnani, Letablier, 2005). A análise das políticas européias que pregam medidas que permitam a conciliação vida profissional/vida familiar para permitir o acesso das mulheres ao emprego (Fagnani, Letablier, 2005, p. I7I) mostra claramente essa interdependência no âmbito europeu.

A adoção de políticas como a APE, na França, em um determinado momento da conjuntura econômica e social, até pode seduzir as mulheres em situações difíceis quanto ao emprego ou à família. Os movimentos sociais em torno do direito ao emprego - e ao pleno emprego - das mulheres, quando existem na França, não são tão fortes como seria de se esperar, e não conseguem fazer frente às medidas de políticas familiares e de emprego adotadas na óptica da "conciliação".

\section{LIMITES SOCIETAIS DA “CONCILIAÇÃO” E DA DELEGAÇÃO}

O caso do Japão mostra como os limites da "conciliação" variam de um espaço societal a outro. As mulheres japonesas conjugam o termo "conciliação", que elas utilizam nas entrevistas (ryoritsu), sob formas e em sentidos muito diferentes, uma vez que atuam em contextos societais, familiares e de casal bastante diferentes daqueles dos países europeus. No caso do Japão, é preciso escolher - o que é muito difícil - entre a maternidade e a carreira, porque "é impossível conciliá-las" (ryoritsu dekinakata).

De fato, uma pesquisa de campo realizada no Japão, em outubro 2003, revelou que, às vezes, existem obstáculos enormes à introdução do modelo da delegação e mesmo do modelo de conciliação vida familiar/vida profissional (em tempo integral) no país (para os primeiros resultados dessa pesquisa, ver Kase, Sugita, 2006). A interrupção da atividade no primeiro filho é a regra, 
o que contrasta com a situação francesa. $\bigcirc$ que mudou nos últimos anos no Japão é que essa interrupção é menos duradoura, e as mães retornam ao mercado de trabalho em busca de um emprego em tempo parcial mesmo com os filhos ainda muito pequenos (menos de um ano).

Entre os principais obstáculos estão a falta de equipamentos coletivos, a falta de políticas públicas que estimulem o trabalho das mulheres em tempo integral, a existência, ao contrário, de políticas que estimulam a inatividade das esposas e sua volta ao trabalho em tempo parcial; e, talvez mais importante ainda, as relações sociais (na família, no casal, na sociedade) e as normas sociais que continuam a negar qualquer legitimidade ao estatuto de trabalhadoras em tempo integral e a possibilidade de carreira às mulheres que têm o estatuto de mães (Hirata, 1996).

Pode-se dizer que o Japão é um caso paradigmático dos limites à conciliação de papéis do ponto de vista das normas, mas também das práticas sociais. A falta de alternativas, tanto do ponto de vista das políticas públicas quanto do ponto de vista dos movimentos sociais, é, sem dúvida, um dos principais fatores explicativos dessa especificidade nacional.

\section{CONCLUSÃO}

Um pensamento crítico da "conciliação" não pode se desenvolver fora do contexto de reflexão sobre as modalidades de reprodução da servidão doméstica.

A socialização familiar, a educação escolar, a formação na empresa, esse conjunto de modalidades diferenciadas de socialização se combinam para a reprodução sempre renovada das relações sociais. As razões dessa permanência da atribuição do trabalho doméstico às mulheres, mesmo no contexto da reconfiguração das relações sociais de sexo a que se assiste hoje, continua sendo um dos problemas mais importantes na análise das relações sociais de sexo/ gênero. E o que é mais espantoso é a maneira como as mulheres, mesmo plenamente conscientes da opressão, da desigualdade da divisão do trabalho doméstico, continuam a se incumbir do essencial desse trabalho doméstico, inclusive entre as militantes feministas, sindicalistas, políticas, plenamente conscientes dessa desigualdade. Mesmo que exista delegação, um de seus limites está na própria estrutura do trabalho doméstico e familiar: a gestão do conjunto do trabalho delegado é sempre da competência daquelas que delegam. É preciso 
refletir não apenas sobre o porquê dessa permanência, mas, principalmente, sobre como mudar essa situação. A nosso ver, é preciso questionar, sobretudo, os âmbitos psicológicos da dominação e a dimensão da afetividade. Essa pesquisa está por ser feita, e é singularmente complicada pela complexidade de seu objeto, que requer um trabalho interdisciplinar de muito fôlego.

\section{REFERÊNCIAS BIBLIOGRÁFICAS}

BROUSSE, C. La Répartition du travail domestique entre conjoints reste très largement spécialisée et inégale. In: Insee/SeDF: France, portrait social 1999-2000. Paris, 1999. p. I35-5I.

CHABAUD-RYCHTER, D.; FOUGEYROLLAS-SCHWEBEL, D.; SONTHONNAX, F. ESpace et temps du travail domestique. Paris: La Librairie des méridiens-Klincksieck, 1985. (Réponses sociologiques)

COLLECTIF. Le Sexe du travail: structures familiales et système productif. Presses Universitaires de Grenoble, 1984.

COMMAILLE, J. Entre famille et travail, les stratégies des femmes. Recherches et Prévisions, n.36, p.3-10, juin. 1994.

DELPHY, C. L'Ennemi principal. Paris: Syllepse, 1998. (Nouvelles questions féministes)

DEVREUX, A-M. Famille. In: HIRATA, H. et al. (coords.) Dictionnaire critique du féminisme. Paris: PUF, 2000. p.66-71.

EHRENREICH, B.; HOCHSCHILD, A. R. (eds.) Global woman: nannies, maids, and sex workers in the new economy. New York: Metropolitan Books; Henry Holt and Co., 2003.

FAGNANI, J.; LETABLIER, M.-T. La Politique familiale française. In: MARUANI, M. (dir.) Femmes, genre et sociétés: l'état des savoirs. Paris: La Découverte, 2005. p. 167-175.

FLIPO, A.; RÉGNIER-LOILIER, A. Articulier vie familiale et vie professionnelle en France: un choix complexe. In: Insee. Données sociales, 2002-2003. Paris, 2002.

FOUGEYROLLAS-SCHWEBEL, D. De la réclusion au cloisonnement: travail domestique et salariat. In: DEFALVARD, H.; GUIENNE, V. Le Partage du travail: bilan et perspectives. Paris: Desclée de Brouwer, 1998. p.157-168.

HAKIM, C. Key issues in women's work: female heterogeneity and the polarisation of women's employment. London, Atlantic Highlands: Athlone, 1996.

HIRATA, H. Division sexuelle du travail et du temps au Japon. In: HIRATA, H.; SENOTIER, D. (dirs.) Femmes et partage du travail. Paris: Syros, 1996. p. 187-198. 
HIRATA, H.; KERGOAT, D. Les paradigmes sociologiques à l'épreuve des catégories de sexe: quel renouvellement de l'épistémologie du travail? In: DURAND J. P.; LINHART, D. Les Ressorts de la mobilisation au travail. Paris: Octarès, 2005. p.263-272.

HIRATA, H.; ZARIFIAN, Ph. Travail (le concept de). In: HIRATA, H. et al. (coords.) Dictionnaire critique du féminisme. Paris: PUF, 2000. p.230-235.

INSTITUT NATIONAL DE LA STATISTIQUE ET DES ÉTUDES ÉCONOMIQUES. France, portrait social 2003-2004. Paris, 2003. Chap.7: Concilier emploi et famille.

KASE, K.; SUGITA, K. (eds.) The Unemployed and unemployment in an international perspective: comparativev studies of Japan, France and Brazil. Tokyo: Institutte of Social Science, University of Tokyo, 2006. (ISS Research Series, 19)

KERGOAT, D. La Division du travail entre les sexes. In: KERGOAT, J. et al. (dir.). Le monde du travail. Paris: La Decouverte, 1998. p.319-327. (Coll. Synos)

Division sexuelle du travail et rapports sociaux de sexe. In: HIRATA, $H$. et al. (dirs.) Dictionnaire critique du féminisme. Paris: PUF, 2000. p.35-44.

LAPEYRE, N.; LE FEUVRE, N. Concilier l'inconciliable ? Le rapport des femmes à la notion de "conciliation travail-famille" dans les professions libérales en France. Nouvelles Questions Féministes, v.23, n.3, p.42-58, 2004.

LAUFER, J. Conciliation vie familiale/vie professionnelle. In: INSTITUT NATIONAL DE LA STATISTIQUE ET DES ÉTUDES ÉCONOMIQUES. Les femmes. Paris: Service des Droits des Femmes/lsee, 1995. p. I63-165. (Coll.: Contours et caractères)

MATHIEU, N.-C. L'Anatomie politique: catégorisations et idéologies du sexe. Paris: Côtéfemmes "Recherches", |991.

NOUVELLES QUESTIONS FÉMINISTES. V.23, n.3, 2004. (Dossier: Famille - Travail: une perspective radicale)

PARREÑAS, R. S. Servants of globalization: women, migration and domestic work. Stanford: Stanford University Press, 2001.

SORJ, B. Reconciling work and family: issues and policies in Brazil. Geneva: International Labour Office, 2004. (Conditions of Work and Employment Series, 8)

TABET P. La Construction sociale de l'inégalité des sexes: des outils et des corps. Paris: L'Harmattan, 1998. (Bibliothèque du féminisme)

Recebido em: maio 2007

Aprovado para publicação em: maio 2007 